\title{
ACTIVE NOISE CANCELLATION
}

\author{
A Degree Thesis \\ Submitted to the Faculty of the \\ Escola Tècnica d'Enginyeria de Telecomunicació de \\ Barcelona \\ Universitat Politècnica de Catalunya \\ by \\ Guillem de la Torre Rovira \\ In partial fulfilment \\ of the requirements for the degree in \\ AUDIOVISUAL ENGINEERING
}

Advisor: Alexander Heldring

Barcelona, June 2017 


\section{Acknowledgements}

Firstly, I would like to express my sincere gratitude to my advisor Prof. Heldring, Alexander for the continuous support of my study and related research, for his patience and motivation.

Besides my advisor, I would also like to thank the Campus Coordination office, for permitting us to carry out the experimentations at the campus park, and the maintenance service staff from UPC Campus Nord, for giving us access to power resources to feed the system. 


\section{Abstract}

Given the recent progresses in Active Noise Cancellation (ANC) for Aircrafts [11], Headphones [10], Telephones [8], etc. I decided to develop an active noise cancellation system for more uncontrolled spaces, like open air spaces. The ANC concept relies on the superposition principle, adding a secondary 'cancelling noise' to the source we want to cancel in order to provoke the opposite perturbation to the air. The difficulty to find a tool to well perform the needed validation tests have make me move into developing an application to be able to test the performance of the ANC systems.

The application has been developed in Python3 language and with Qt5 Designer for the interface. It incorporates the implementation of four ANC systems, the first one being the simplest approach, of increasing complexity arriving to an adaptive LMS based filtering approach. In this last approach, a microphone is used to capture the cancellation error to adapt the filtering stage in order to improve the cancellation in real-time.

Some tools have been developed to have more control of the experimentation parameters like an equalizer, a signal generator offering some signal options, or a graphics visualizer to have real-time monitoring of the experimentation progress. 


\section{Resum}

Donats els recents progressos en Cancel-lació Activa de Soroll (CAS) per a Avions [11], Cascos de música [10], Telèfons [8], etc. vaig decidir desenvolupar un sistema de cancel-lació activa de soroll per espais menys controlats, com els espais a l'aire lliure. El concepte de la CAS es basa en el principi de superposició, afegint un "soroll cancel·lador" al de la font que volem cancel·lar amb l'objectiu de provocar la perturbació oposada a l'aire. La dificultat per trobar una eina per dur a terme correctament els testeigs de validació necessaris, m'ha fet reconsiderar els objectius i acabar desenvolupant un aplicatiu per testejar el rendiment dels sistemes de cancel·lació activa.

L'aplicatiu ha estat desenvolupat amb el llenguatge Python3 i el dissenyador d'interfícies Qt5 Designer. Aquest incorpora la implementació de quatre sistemes de CAS, el primer essent l'aproximació més simple, que creixen de complexitat arribant a una representació que inclou un filtrat LMS adaptatiu. En aquesta última s'utilitza un micròfon per capturar l'error de cancel·lació i adaptar el filtrat tot millorant la cancel.lació a temps real.

S'han desenvolupat algunes eines per tenir més control dels paràmetres de l'experimentació com un equalitzador, un generador de senyals oferint diferents tipus de senyals possibles, o un visualizador de gràfiques per mantenir un monitoratge en temps real del progrés de l'experimentació. 


\section{Resumen}

Dados los recientes progresos en Cancelación Activa de Ruido (CAR) par Aviones [11], Cascos de música [10], Teléfonos [8], etc. decidí desarrollar un sistema de cancelación activa de ruido para espacios menos controlados como es el caso de los espacios al aire libre. El concepto de la CAR reside en el principio de superposición, añadiendo un "ruido cancelador" a la fuente que queremos cancelar con el objetivo de provocar la perturbación opuesta en el aire. Las dificultades por encontrar una herramienta para llevar a cabo los test de validación necesarios, me han hecho reconsiderar los objetivos y acabar desarrollando un aplicativo para testear el rendimiento de los sistemas de cancelación activa.

El aplicativo se ha desarrollado usando el lenguaje Python3 y el diseñador de interfaces Qt5 Designer. Incorpora la implementación de cuatro sistemas de CAR, el primero siendo el enfoque más simple, que van creciendo en cuanto a complejidad hasta llegar a un enfoque basado en filtrado adaptativo LMS. En este último se usa un micrófono para captar el error de cancelación y adaptar el filtrado para mejorar la cancelación en tiempo real.

Se han desarrollado algunas herramientas para tener más control de los parámetros de la experimentación, como un ecualizador, un generador de señales ofreciendo diferentes tipos de señal, o un visualizador de gráficas para monitorizar en tiempo real el progreso de la experimentación. 


\section{Table of contents}

$\begin{array}{lr}\text { Acknowledgements } & 1\end{array}$

$\begin{array}{ll}\text { Abstract } & 2\end{array}$

Resum 2

$\begin{array}{lr}\text { Resumen } & 4\end{array}$

$\begin{array}{ll}\text { Table of contents } & 5\end{array}$

$\begin{array}{lr}\text { List of Figures } & 6\end{array}$

$\begin{array}{ll}\text { List of Tables } & 7\end{array}$

1. Introduction 8

1.1. ANC Principle 8

1.2. Objectives $\quad 8$

1.3. Organisation 9

2. State of the art of the technology used or applied in this thesis 11

$\begin{array}{ll}\text { 2.1. Early Developments } & 11\end{array}$

$\begin{array}{ll}\text { 2.2. Recent Advances } & 11\end{array}$

3. Methodology / project development 12

3.1. Application Structure 12

3.2. Signal Generator 13

$\begin{array}{ll}\text { 3.3. Distance Checker } & 14\end{array}$

$\begin{array}{lr}\text { 3.4. Equalizer } & 14\end{array}$

$\begin{array}{ll}\text { 3.5. Graphics Viewer } & 15\end{array}$

3.6. Experiment Types and Setup 16

4. Results 23

5. Budget 25

6. Environment Impact 26

7. Conclusions and future development: 27

$\begin{array}{lr}\text { Bibliography } & 28\end{array}$ 


\section{List of Figures}

Figure1. Signal Cancellation of two waves $180^{\circ}$ out of phase. ("Active Noise-Cancellation Project", by Kuang-Hung liu et al., 2008.) pg.8

Figure 2. Project Gantt Diagram pg.10

Figure 3. Process of silencing sound oscillations (P. Lueg 1936) pg.11

Figure 4. Block diagram of adaptive noise cancellation system (M. Ramli et al. 2012) pg.11

Figure 5. Application interface pg.12

Figure 6. Application analytic UML back-end description pg.13

Figure 7. Signal Generator interface pg.13

Figure 8. Distance Checker interface pg.14

Figure 9. Equalizer interface pg.14

Figure 10. Butterworth filter-bank pg.15

Figure 11. Butterworth filtering comparison pg.15

Figure 12. Graphics viewer interface pg.15

Figure 13. Experimentation type and setup interface pg.16

Figure 14. Experimentation Type 1 interface and Cancellation amount controller pg.17

Figure 15. Experimentation type 1 Concept description pg.18

Figure 16. Experimentation type 1 block-diagram pg.19

Figure 17. Experimentation Type 2 interface pg.20

Figure 18. Experimentation Type 3 interface pg.21

Figure 19. Experimentation Type 2 block-diagram pg.21

Figure 20. Experimentation Type 4 interface pg.22

Figure 21. Experimentation Type 4 lock-diagram pg.22

Figure 22. Cancellation amount for a $100 \mathrm{~Hz}$ tone pg.23

Figure 23. Cancellation dependent on frequency pg.23

Figure 24. Cancelled noise until $500 \mathrm{~Hz}$ pg.24

Figure 25. Cancelled noise until $4 \mathrm{kHz}$ pg.24

Figure 26. Cancellation amount comparison of systems Type 1 and Type 2 for a $100 \mathrm{~Hz}$ pure tone pg.24 


\section{List of Tables:}

Table 1. Work package 1: Research pg.9

Table 2. Work package 2: Experimentations pg.9

Table 3. Work package 3: Programming pg.9

Table 4. Work package 4: Documentation pg.10

Table 5. Milestones pg.10

Table 6. Material Costs pg.25

Table 7. Personal Costs pg. 25 


\section{Introduction}

During the last decades, interest in noise pollution has grown likewise the number of tools to face the problem. In noise control, we can differentiate two methods: passive and active. Until now, the mainly used method has been the passive one, in which sound barriers and variating absorption materials are used to block sound transmissions or to resurface spaces to alter their response. Nowadays vast improvements in active noise cancellation(i.e. ANC) have made these type of solutions to become increasingly important, especially for those low audio frequencies $(20 \mathrm{~Hz}-160 \mathrm{~Hz})$ where passive methods encounter more difficulties. The application fields are being, on one hand, the industry (machinery vibrations reduction, ventilation ducts, heating systems, etc.) and, on the other hand, very controlled environments like aircraft cabins, automobiles, phone and video calls and headphones, in which the progress is resulting very significant.

\subsection{ANC Principle}

The Active Noise Cancellation concept relies on the superposition principle. In order to achieve the ANC, a "cancelling signal" is reproduced by a secondary source in order to cause a destructive interference which would cancel the unwanted noises of the primary source (Fig.1). The biggest challenge is to identify the primary source without any delay in order to well perform the superposition and minimize, therefore, the residual noise after cancellation.

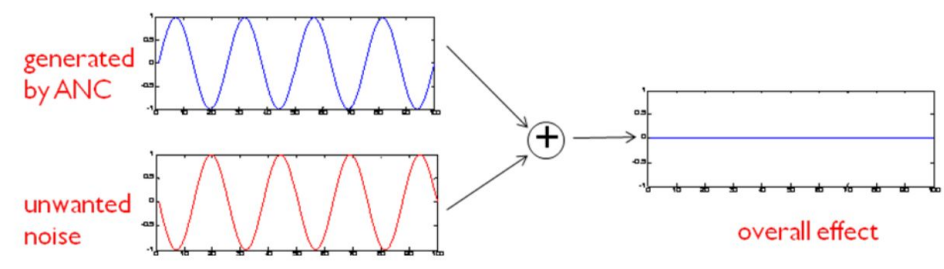

Figure 1. Signal Cancellation of two waves $180^{\circ}$ out of phase (Kuang-Hung liu et al. 2008)

\subsection{Objectives}

Given the recent progresses in active noise cancellation and its potential application fields, I have seen the opportunity to study this type of systems for outdoor open spaces, which are less controlled and less investigated environments. Nevertheless, the absence of interfaces to test this type of systems has made very difficult to carry out the planned experimentations. Therefore the objectives of this work have been the development and implementation of an application to test different active noise cancellation systems and the analysis of their performance in outdoor spaces.

The application has four different systems to test, the two first ones are static simple approaches in which the unwanted noise is previously known or instantaneously captured and then just cancelled. The two last ones are adaptive solutions based on LMS error.

The only equipment required has been: a computer with a python3 interpreter installed (with numpy, sounddevice, Pyqt5, scipy and matplotlib libraries installed), two speakers, two directional microphones, an audio card with 2 inputs and 2 outputs, a sonometer and the corresponding wiring. 


\subsection{Organisation}

In order to achieve these objectives, the work plan has been organized in the following work packages:

\begin{tabular}{|l|l|}
\hline Project: Research & WP ref: 1 \\
\hline $\begin{array}{l}\text { Short description: } \\
\text { The Research package is planned to be executed mainly before, } \\
\text { but also during the experimentations. It comprehends the } \\
\text { different research areas to well understand the existing ANC } \\
\text { Systems and their possible limitations. }\end{array}$ & $\begin{array}{l}\text { Planned start date: } 27 / 02 / 2017 \\
\text { Planned end date: } 21 / 04 / 2017\end{array}$ \\
\cline { 2 - 2 } & $\begin{array}{l}\text { Start event: 27/02/2017 } \\
\text { End event: 25/04/2017 }\end{array}$ \\
\hline $\begin{array}{l}\text { Internal task T1: ANC Concept } \\
\text { Internal task T2: ANC System Examples } \\
\text { Internal task T3: Sound Propagation } \\
\text { Internal task T4: Adaptive filters } \\
\text { Internal task T5: Experimentations evaluation and Further Research }\end{array}$ \\
\hline
\end{tabular}

Table 1. Work package 1: Research

\begin{tabular}{|c|c|}
\hline Project: Experimentations & WP ref: 2 \\
\hline \multirow{3}{*}{$\begin{array}{l}\text { Short description: } \\
\text { The Experimentations are the basis of this project given that they } \\
\text { will allow us to review and improve the test application and } \\
\text { understand the ANC systems behavior and their viability. }\end{array}$} & Planned start date: 20/03/2017 \\
\hline & \\
\hline & $\begin{array}{l}\text { Start event:20/03/2017 } \\
\text { End event:19/06/2017 }\end{array}$ \\
\hline \multicolumn{2}{|c|}{$\begin{array}{l}\text { Internal task T1: Experimentation } 1 \text { (ANC in open spaces with a cancelling loudspeaker) } \\
\text { Internal task T2: Experimentation } 2 \text { (Exp App test1: static tone generator and automatic distance checker) } \\
\text { Internal task T3: Experimentation } 3 \text { (Exp App test2: EQ) } \\
\text { Internal task T4: Experimentation } 4 \text { (ANC with a known source) } \\
\text { Internal task T5: Experimentation } 5 \text { (ANC with unknown source) } \\
\text { Internal task T6: Experimentation } 6 \text { (ANC with error evaluation and predictors adaptation) }\end{array}$} \\
\hline
\end{tabular}

Table 2. Work package 2: Experimentations

\begin{tabular}{|l|l|l|}
\hline Project: Programming & WP ref: 3 \\
\hline Short description: & \multicolumn{2}{|l|}{ Planned start date: 06/03/2017 } \\
The Programming package is conceived as a framework to well & Planned end date: 23/06/2017 \\
\cline { 2 - 3 } $\begin{array}{l}\text { perform the experimentations. It is based on an Exp's App } \\
\text { design, implementation and further modifications. }\end{array}$ & \multicolumn{2}{|l|}{ Start event: 06/03/2017 } \\
\hline \multicolumn{2}{|l|}{ End event: 30/06/2017 } \\
\hline Internal task T1: Experimentations App Design & Deliverables: & Dates: \\
Internal task T2: Experimentations App Implementation & Exp. App v1 & $20 / 03 / 2017$ \\
Internal task T3: Experimentations App First Modification & Exp. App v2.1 & $17 / 04 / 2017$ \\
Internal task T4: Experimentations App Second Modification & Exp. App v2.2 & $08 / 05 / 2017$ \\
Internal task T5: Experimentations App Third Modification & Exp. App v2.3 & $29 / 05 / 2017$ \\
\hline
\end{tabular}

Table 3. Work package 3: Programming 


\begin{tabular}{|c|c|c|}
\hline Project: Documentation & \multicolumn{2}{|l|}{ WP ref: 5} \\
\hline \multirow{3}{*}{$\begin{array}{l}\text { Short description: } \\
\text { The Documentation package is conceived to have an idea of } \\
\text { the necessary time to write the documentation and, therefore, } \\
\text { when this composition should start. }\end{array}$} & \multirow{2}{*}{\multicolumn{2}{|c|}{$\begin{array}{l}\text { Planned start date: } 06 / 03 / 2017 \\
\text { Planned end date: } 30 / 06 / 2017\end{array}$}} \\
\hline & & \\
\hline & \multicolumn{2}{|c|}{$\begin{array}{l}\text { Start event:06/03/2017 } \\
\text { End event: }\end{array}$} \\
\hline Internal task T1: Project Proposal and Work Plan & Work Plan & $10 / 03 / 2017$ \\
\hline Internal task T2: Critical Design Review & Critical Review & $28 / 04 / 2017$ \\
\hline Internal task T4: Experimentations Documentation & Exp. Report & $15 / 05 / 2017$ \\
\hline Internal task T5: Final Report & Final Report & $30 / 06 / 2017$ \\
\hline
\end{tabular}

Table 4. Work package 4: Documentation

\begin{tabular}{|c|l|l|l|l|}
\hline WP\# & Task\# & Short title & Milestone / deliverable & Date (week) \\
\hline 3 & T2 & Exp. App Implementation & Exp. App v1 & $20 / 03 / 2017$ \\
\hline 3 & T3 & Exp. App First Modification & Exp. App v2.1 & $17 / 04 / 2017$ \\
\hline 3 & T4 & Exp. App Second Modification & Exp. App v2.2 & $08 / 05 / 2017$ \\
\hline 3 & T4 & Exp. App Third Modification & Exp. App v2.3 & $29 / 05 / 2017$ \\
\hline 5 & T1 & Work Plan & Work Plan & $10 / 03 / 2017$ \\
\hline 5 & T2 & Critical Design Review & Critical Review & $10 / 05 / 2017$ \\
\hline 5 & T3 & Experimentations Documentation & Experimentations Report & $19 / 06 / 2017$ \\
\hline 5 & T3 & Final Report & Final Report & $30 / 06 / 2017$ \\
\hline
\end{tabular}

Table 5. Milestones

Some incidences have forced the original plan to be modified towards this one. The first experimentation revealed that the application approach was too simple to well perform the experimentations and appreciate the expected results. The first experimentations block was then reconceived, as the below gantt diagram (Fig.2) shows, to redefine and test the final application to well perform the expected ANC tests.

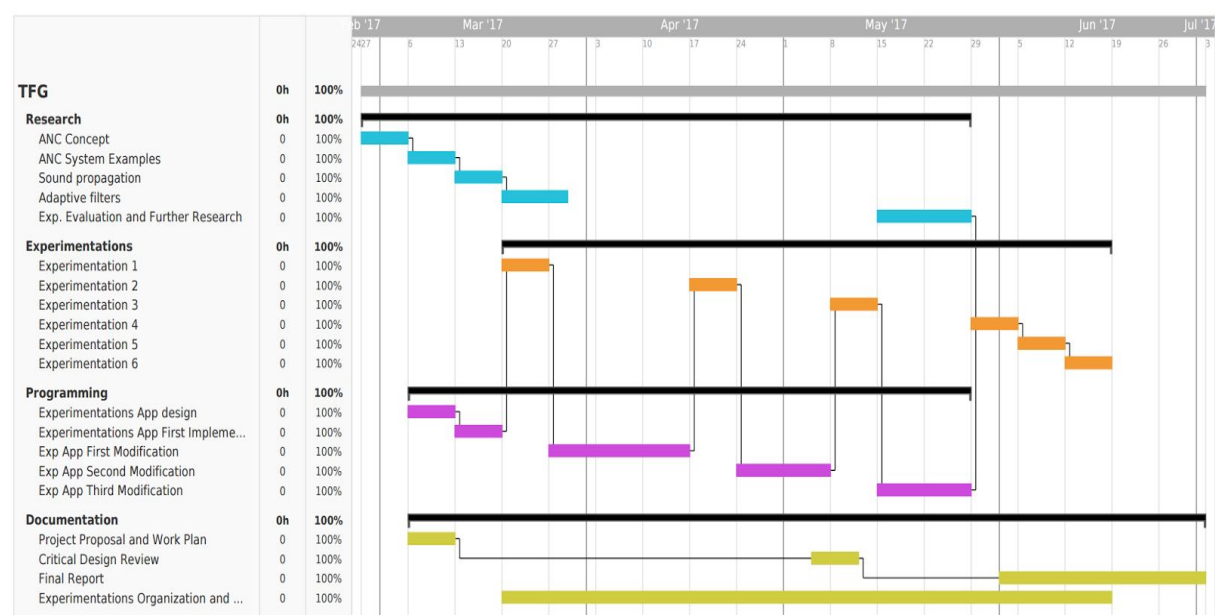

Figure 2. Project Gantt Diagram

This has forced the experimentations for concept validation to be shifted to the end of the Gantt diagram to wait for having a working application.

Once noticed that the most important task to well perform the different experimentations was to reconceive the experimentations application, it has taken much more time than expected to develop the wanted experimentations framework which has forced the re-conceptualization of the project. 


\section{State of the art of the technology used or applied in this thesis:}

\subsection{Early developments}

In 1936 the Active Noise Control concept appears for the first time in Paul Lueg's patent "Process of silencing sound oscillations" (U.S. Patent 2,043,416) [1]. Paul Lueg described in his patent how to cancel sinusoidal tones in ducts by decaying the phase of the wave and inverting the polarity (Fig.3).

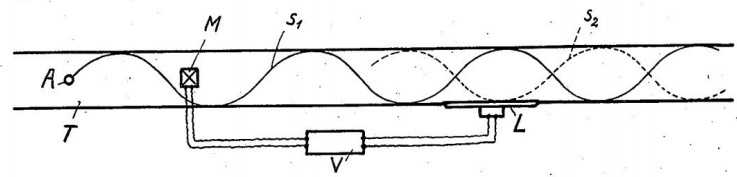

Figure 3. Process of silencing sound oscillations (P. Lueg 1936)

Twenty years later, Olson and May (1953) described their electronic sound absorber [2] as "a novel absorber for low frequency sound waves which is economical of space, [...] an absorber as set forth which is electronically operated.", marking the beginning of the personal silent areas based on feedback active noise control system. In their system the unwanted noise is detected by a microphone and fed back, once filtered, to a loudspeaker located close to the microphone.Hawley and Simshauser (1953) developed the first ANC headsets opening a new huge area inside the personal silent areas based on ANC[3].

\subsection{Recent advances}

Since these first proposals, a number of developments have been carried out in this research area. Based on Olson's and Lueg's work, Widrow (Widrow et al, 1975) suggests an adaptive LMS filtering approach and its implementation by DSP's[ ] giving a new dimension to the subject. Once the adaptive filtering proposal appeared, many different approaches (feedback, feed-forward, hybrid, etc.) and filter modifications (FxLMS, FuLMS, NLMS, RLMS, etc.) have been developed.

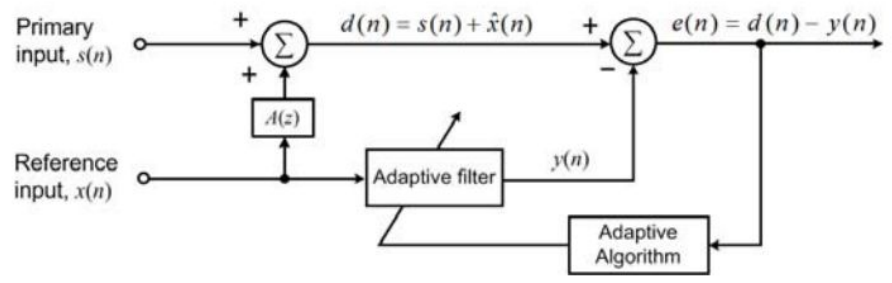

Figure 4. Block diagram of adaptive noise cancellation system (Roshahliza M. Ramli et al. 2012)

Nowadays the usage of these type of systems is growing very fast. From Burgess' (1981) application in ducts, we can see the ANC systems in industrial installations, automobiles, aircrafts, heating, video calls and the most recent ANC applications for Headphones (Emborg, 1994; Hirsch, 1999; Sas, 1998; Sen M. Kuo, 2006; Guldenschuh, 2012; Lloyd, 2015). 


\section{Methodology / project development:}

The main and hardest part of the project has been the development of an application to test different types of ANC systems. The application has been conceived as a test environment to carry out all the needed experimentations, therefore it not only comprehends the different systems to test, but also some tools to well perform the experimentations.

\subsection{Application Structure}

The front-end of the application has been developed with Qt Designer to learn a new interface designing environment which is open source and free, even for commercial projects, multi-language and multi-platform (Fig.5).

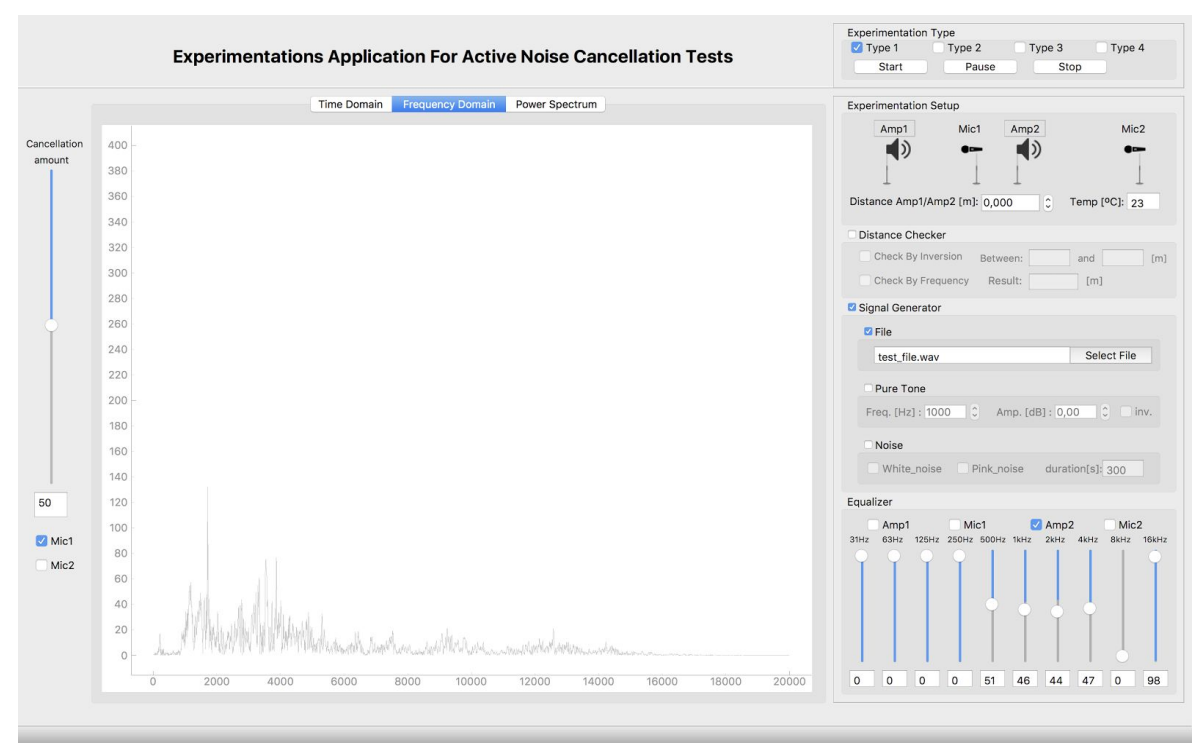

Figure 5. Application interface

The back-end has been developed with python for its simplicity and to make use of some toolkits as "sounddevice", permitting to manipulate and stream audio on almost any soundcard connected to the computer, or "pyQt5" permitting to link the front end with the python backend with the same programming language.

As shown on Figure 6, the application is based on a Main class which serves the user interface and work as a link between the front-end and the back-end of the application. An object from the Signal Generator class uses the information given by the user to generate the desired test signal. The Distance Checker class serves as a checker to find the distances of the experimentation setup for which the cancellation is better performed. The Equalizer is based on the Filterbank class and can be used to filter any input or output signal separately and simultaneously. Finally, for the audio and graphs processing, a multithreading approach has been implemented. This approach helps to minimize audio and graphs processing cost by making them work on different threads, each one with its callback function. 


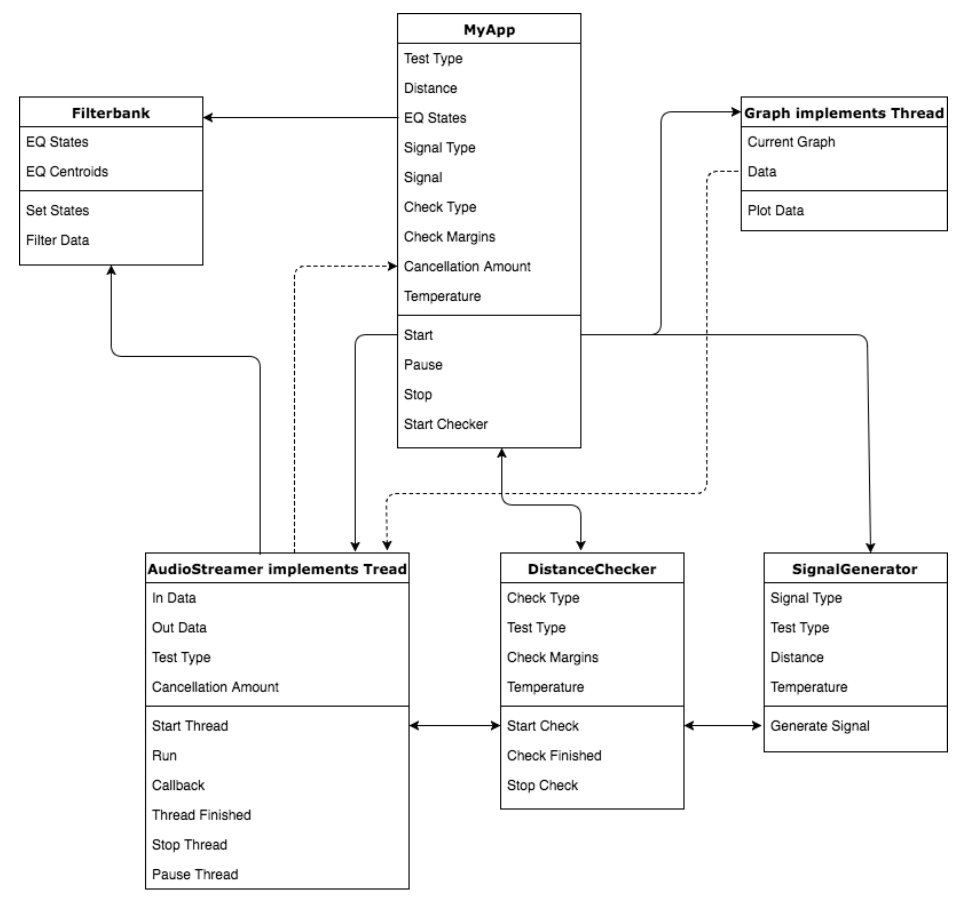

Figure 6. Application analytic UML back-end description.

\subsection{Signal Generator}

The Signal Generator is responsible of generating the desired test signal from the data given in the interface. The interface permits to choose between three types of signal to test, the signal can be any audio file, a pure tone or a noise.

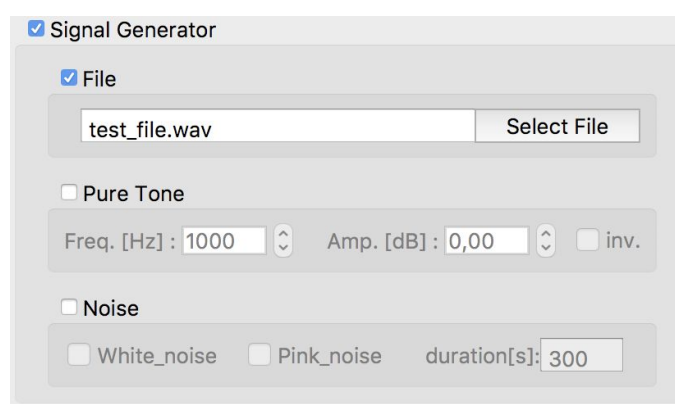

Figure 7. Signal Generator interface

\section{a) File}

The file option generates the signal from a given audio file. The "Select File" button opens a popup window which allows the user to select any audio file (.wav, .mp3 or .aiff) from the computer file system.

\section{b) Pure Tone}

The "Pure Tone" box generates a pure tone from a given frequency (in Hertz) and amplitude (in $\mathrm{dB}$ ). The maximum amplitude corresponds to $0 \mathrm{~dB}$, all other amplitudes are in negative $\mathrm{dB}$. The tone generator is conceived to generate stationary tones with no phase divergence for two speakers in order to test the standard superposition phenomenon. 
Nevertheless, a checkbox has been added in order to be able to decay the cancelling speaker's tone phase, from a given distance, with respect to the source to be cancelled and invert it, like the ANC systems do.

\section{c) Noise}

The "Noise" box is used to generate a white or pink noise as test signal, with a given duration in seconds.

\subsection{Distance Checker}

The Distance Checker has been conceived as a tool for finding the desired distance between a given margins (in meters) with a precision of $0,8 \mathrm{~m}$ for a sampling frequency of $44100 \mathrm{samp} / \mathrm{sec}$. Two approaches have been implemented: the check by inversion and the check by frequency approaches.

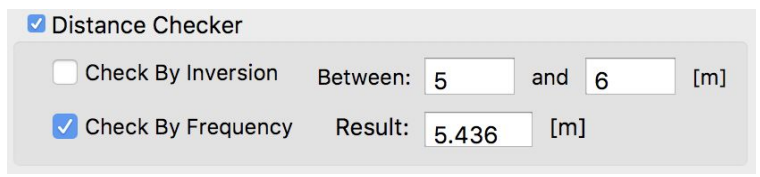

Figure 8. Distance Checker interface

\section{a) Check By Inversion}

In the Check By Inversion approach, the cancelling signal is decayed by one sample, each frame, with respect to the source one. A test microphone signal is analyzed in order to find the frame of minimum bandpass power, which delay corresponds to the resulting distance.

\section{b) Check By Frequency}

In the Check By Frequency approach, a pure tone is generated, for each frame, with no phase decay between the source and the cancelling speaker. As the check by inversion approach, a test microphone signal is analyzed in order to find the frame of minimum power which frequency corresponds to the resulting distance.

\subsection{Equalizer}

An Equalizer has been designed to have more versatility on the tests, giving the user the opportunity to filter any of the 2 inputs or 2 outputs simultaneously with a different equalization each. This way every band can be analyzed separately or, for example, apply a cancellation over a source signal but only for the lowest frequencies.

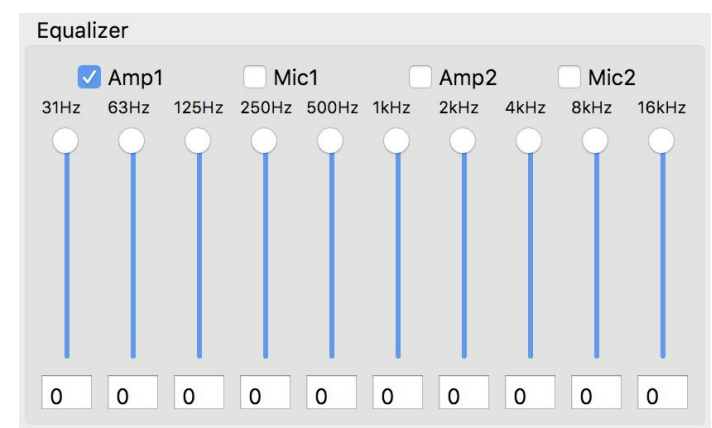

Figure 9. Equalizer interface 
The implemented EQ consists in an 10-band octave filterbank. The chosen filters have been the Butterworth ones of fifth order, also referred as maximally flat magnitude filters, introduced by Butterworth in 1930 [12]. These filters have been chosen because they have the flattest and widest possible frequency response on their passband without ripples.

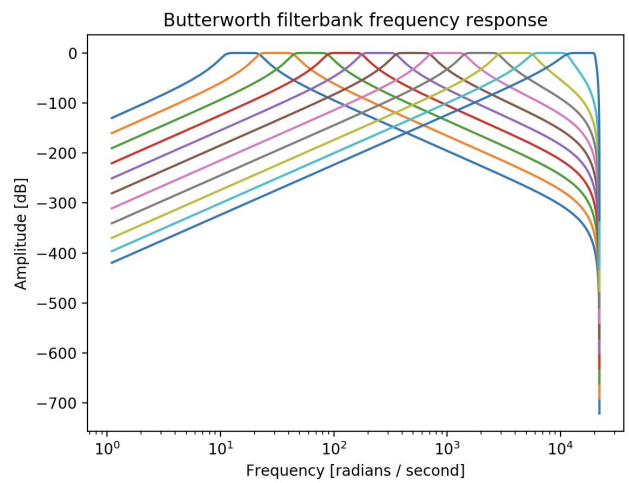

Figure 10. Butterworth filter-bank

Due to the phase shift of the analog filters a forward-backward filtering approach has been implemented, which cancels any phase shift (Fig.11), reaching a zero-phase filtering approach with IIR filters.

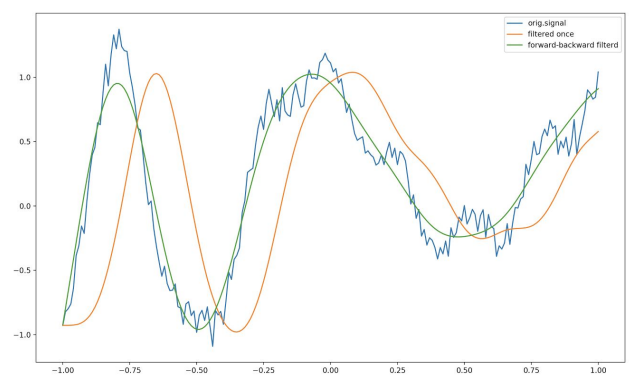

Figure 11. Butterworth filtering comparison

\subsection{Graphics Viewer}

The application is also equipped with a graph visualizer to see the signal captured by each microphone in real-time. Three graph types are provided: the amplitude in time domain and in frequency domain, and a power spectrum plot.

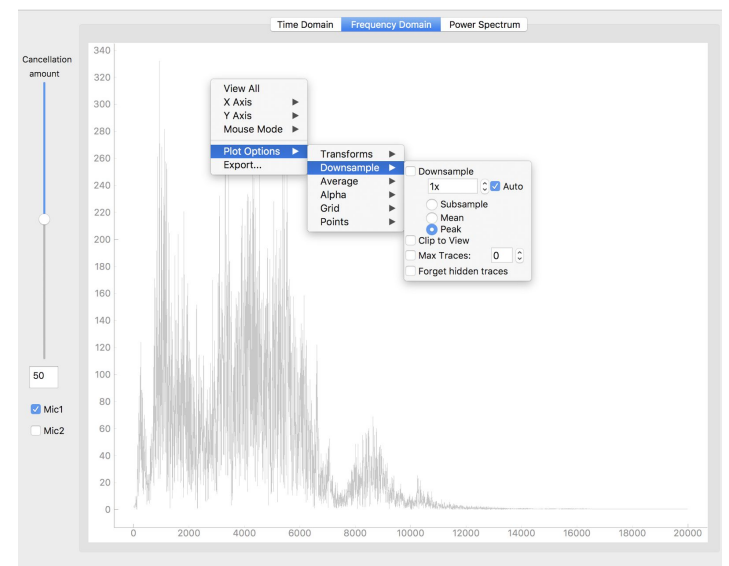

Figure 12. Graphics viewer interface 
Due to the big computational cost of the graph viewer, a multithreading approach has been implemented. Having the audio stream and the user interface already running in separate threads, another thread has been implemented to take care of the graphics plotter, in order to avoid overloading the system.

Apart from having the three selectable graps (time domain, frequency domain and power spectrum), each type of plot can be moved and zoomed with the laptop trackpad or the classical [Ctrl.+], [Ctrl.-] controls. In addition, clicking the mouse's right button, a pop-up menu appears with some options like exporting the graph, domain transformation, downscaling, etc. (Fig.12)

\subsection{Experiment Types and Setup}

The experiments are designed to work with an external sound card with two inputs and two outputs and the corresponding two speakers and two microphones. For better performance, the two speakers and the two microphones should respectively be the same brand and model in order to have the most similar frequency and temporal response possible. If they are not equal, the octave-band equalizer is provided to filter any input or output from the system.

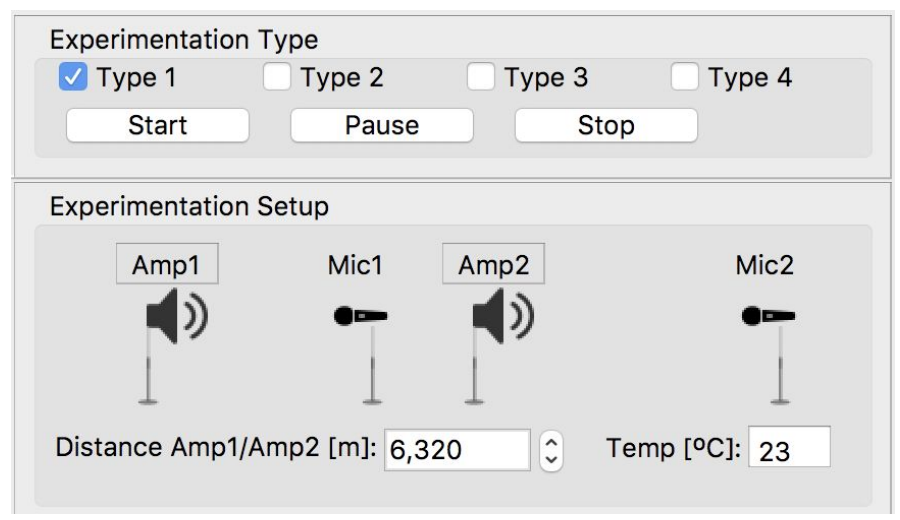

Figure 13. Experimentation type and setup interface

Four different ANC systems with increasing complexity have been implemented in order to be applied and tested. The "Experimentation Type" box has four checkboxes to select the desired system and the Start, Pause and Stop buttons to manage the experimentation (Fig.13).

A setup box is also provided to have an idea of the setup of the current experimentation and, once settled up, bring the details of the installation back to the program. The needed information to perform the wanted test are the corresponding installation distances and the ambient temperature.

The ambient factors are taken in account to have a more accurate idea of the sound propagation speed in the test environment (equation 1). 


$$
\begin{gathered}
\qquad \begin{array}{c}
c=20,05 \sqrt{T+e / p} \quad[\mathrm{~m} / \mathrm{s}] \quad \text { equation } 1 \\
\text { where }: T=\text { absolute temperature }\left[{ }^{\circ} \mathrm{K}\right] \\
e=\text { partial pressure of water vapor }[\mathrm{psi}] \\
p=\text { barometric pressure }[\mathrm{psia}]
\end{array}
\end{gathered}
$$

Nevertheless dependence on humidity is neglected because in the atmosphere it is not common to have large humidity gradients in a constant altitude. Therefore, the following simplification has been chosen (equation 2) which comprehends the transformation to the Celsius degree metric system.

$$
c=20,05 \sqrt{\tau+273,15} \quad[\mathrm{~m} / \mathrm{s}] \quad \text { equation } 2
$$

where: $\tau=$ absolute temperature $\left[{ }^{\circ} \mathrm{C}\right]$

Taking the two first terms of the Taylor polynomial expansion the above equation results in the equation 3 , where the 331,3 constant represents the sound propagation speed through the air at $0^{\circ} \mathrm{C}$ in dry air.

$$
c=(331,3+0,606 \cdot \tau) \quad[\mathrm{m} / \mathrm{s}]
$$

equation 3

\section{a) ANC System Type 1}

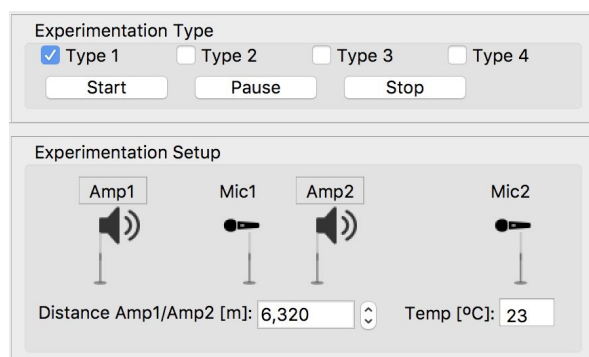

Figure 14. Experimentation Type 1 interface and Cancellation amount controller

The first system implemented is the simplest ANC approach. In this implementation a test signal is sent through the first amplifier as the source to be cancelled. Simultaneously, the second amplifier is sending the same signal but with a delay ' $\delta$ ' obtained from the equation 4 and inverted.

$$
\begin{aligned}
& \delta=d / c \quad[\text { seconds }] \\
& \text { where: } d=\text { distance }[\mathrm{m}] \\
& c=\text { sound celerity }[\mathrm{m} / \mathrm{s}] \\
& p=\text { barometric pressure }[p s i a]
\end{aligned}
$$

\section{equation 4}




\section{$\delta^{\prime}=d / c \cdot f s \quad[$ samples $] \quad$ equation 5}

where : $f s=$ sampling frequency [samples/second]

The expected result is to obtain a 'hearing zone' in front of the first source in which the sent message should be well heard, with any distortion. On the other hand, in front of the second speaker, the cancellation should occur, at least for the lower frequencies, for which wavelength dimensions give a better tolerance to achieve the cancelling superposition.

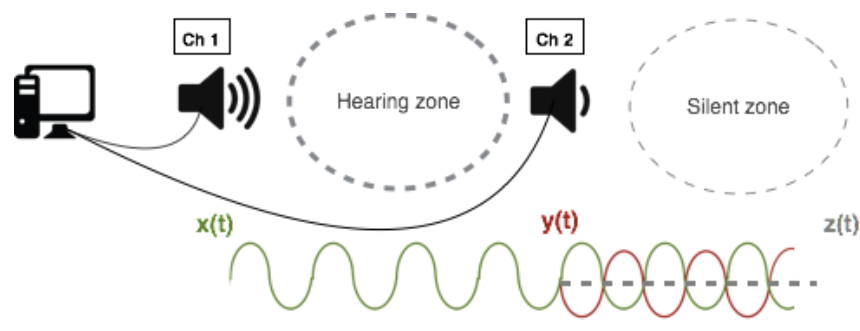

Figure 15. Experimentation type 1 Concept description

Supposing to have a listener in the silent zone at distances $d_{1}$ and $d_{2}$ from the Source one and the source 2 respectively (Fig.15). The objective is to obtain the expected cancellation at the listener's position, by introducing a delay $\delta=\left(d_{1}-d_{2}\right) / c$ (depending only on the distance between sources $D=d_{1}-d_{2}$ ) on the second channel signal $y(t)$ and inverting it (equation 6).

$$
y(t)=-x\left(t-\left(d_{1}-d_{2}\right) / c\right)
$$

equation 6

The cancelled signal $z(t)$ is then the resulting of the equation 7 .

$$
z(t)=x\left(t-\delta_{1}\right)+y\left(t-\delta_{2}\right)=x\left(t-d_{1} / c\right)+y\left(t-d_{2} / c\right) \quad \text { equation } 7
$$

By substituting $y(t)$ we get:

$$
z(t)=x\left(t-d_{1} / c\right)-x\left(t-d_{2} / c-\left(d_{1}-d_{2}\right) / c\right)=x\left(t-d_{1} / c\right)-x\left(t-d_{1} / c\right)=0
$$

Nevertheless, the attenuation due to the distance is not taken in account. So a gain stage must be taken in account in the equation. For this reason, a volume slider is provided to update in real-time the overall gain of the cancelling amplifier (Fig.14). To achieve cancellation, the canceling amplifier's gain must be lower than a certain fraction of the source's because of the attenuation effect given by the distance.

The sound intensity level $L_{i}$ (in $\mathrm{dB}$ ) from the equation 9 is obtained from the intensity $I$ equation for a given distance $r$ from the source (equation 8 ).

$$
\begin{array}{lll}
I=\frac{W}{4 \pi r^{2}} \quad\left[\mathrm{Watt} / \mathrm{m}^{2}\right] & \text { equation } 8 \\
L_{i}=10 \log _{10}\left(\frac{I}{I_{0}}\right) & {[\mathrm{dB}]} & \text { equation } 9
\end{array}
$$

The objective is to produce a "silent zone" in front of the cancelling speaker as depicted in 
figure 15. If we consider two sources at distances $d_{1}$ and $d_{2}$ from the listener, the difference between the sound intensity level produced by the first source $L_{i, 1}$ and the second one $L_{i, 2}$ is given by the equation 8 .

$$
\begin{aligned}
L_{i, 1} & -L_{i, 2}=10 \log _{10}\left(\frac{I_{1}}{I_{2}}\right) \quad[d B] \quad \text { equation } 10 \\
& =10 \log _{10}\left(\frac{W_{1} \cdot d_{2}{ }^{2}}{W_{2} \cdot d_{1}{ }^{2}}\right)
\end{aligned}
$$

To reach a perfect cancellation this sound intensity level difference must be zero.The following equation shows the relation between distance and power for both sources to reach the same intensity level at the listener's position.

$$
\begin{array}{cr}
L_{i, 1}-L_{i, 2}=0 \Leftrightarrow W_{1} \cdot d_{2}^{2}=W_{2} \cdot d_{1}^{2} & \text { equation } 11 \\
W_{2}=W_{1} \cdot\left(\frac{d_{2}}{d_{1}}\right)^{2} & \text { equation }
\end{array}
$$

The gain $G$ of the second source can be represented as in the following equation in Decibels.

$$
\begin{aligned}
G=10 \log _{10}\left(\frac{W_{2}}{W_{1}}\right) & =10 \log _{10}\left(W_{1} \cdot\left(\frac{d_{2}}{d_{1}}\right)^{2}\right)-10 \log _{10}\left(W_{1}\right) \\
\Rightarrow G & =-20 \log _{10}\left(\frac{d_{1}}{d_{2}}\right) \quad[d B] \quad \text { equation } 13
\end{aligned}
$$

The system diagram can then be depicted as follows (Fig.16), with a delay $T_{0}=D / c[s]$ (where $D=$ distance between sources $d_{1}-d_{2}$ ) and a gain $G[d B]$ obtained from the equation 13.

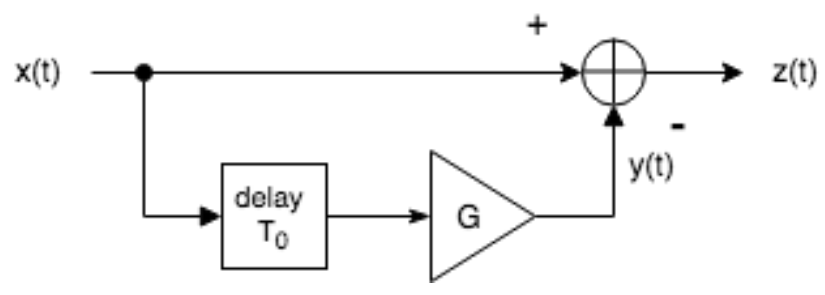

Figure 16. Experimentation type 1 block-diagram

However, this implementation reveals a big problem: the relation of the distance between the listener, for which the cancellation should occur, and the cancelling speaker with respect to the distance between sources, determines the effectivity range of the cancellation.

If the listener is close to the cancelling speaker, with respect to the distance between speakers, the cancelling speaker power will be significantly smaller than the noise source power. This would cause that, a listener who was much further than the first one, would integrate both sources, and the cancellation would be weaker. For a meaningful cancellation range, the first listener for which the cancellation must occur should be, at least, two times further from the cancelling speaker than the distance between sources, obtaining an effective cancelling range (a cancellation deviation less than $3 \mathrm{~dB}$ ) of more than eighty times the distance between sources. 


\section{b) ANC System Type 2}

The first approach is of relevance to study the superposition phenomenon by itself. Nevertheless, in a real situation with an unwanted noise to be cancelled, a more autonomous approach should be applied, in which the signal being emitted by the source to be cancelled is unknown.

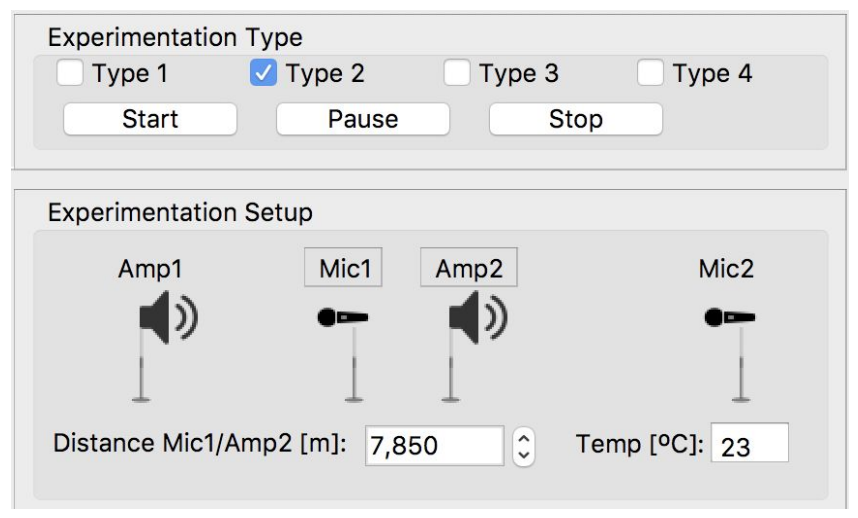

Figure 17. Experimentation Type 2 interface

In this second approach, a microphone is placed between the noise source and the cancelling speaker to capture the unwanted noise in order to be processed and cancelled. The concept of this second approach is the same than the first one, taking the microphone as the reference source. The drawback is that this processing must be on real time, therefore the minimum distance between the microphone and the cancelling speaker depends on the frame size of the audio streamer. To avoid missing the captured frame, once processed, at the instant which it passes at the level of the cancelling speaker, this distance must be greater than the distance ' $D$ ' described in the equation below (equation 14).

$$
\begin{gathered}
D=\frac{F}{f_{s}} \cdot c \quad[\mathrm{~m}] \\
\text { where }: F=\text { frame size }[\text { samples }] \\
c=\text { sound celerity }[\mathrm{m} / \mathrm{s}] \\
f_{S}=\text { sampling frequency }[\text { samples } / \mathrm{s}]
\end{gathered}
$$

\section{equation 14}

In our case, due to the big computational load of the graphics, the equalizer and the real-time interactive interface, the minimum frame size is 1000 samples for a sampling frequency of $44100 \mathrm{~Hz}$, so the minimum distance is about seven meters. Without graphics and filtering the frame can be reduced up to the 300 samples which corresponds to a distance of 2.35 meters.

In this approach the cancellation amount depends directly on the gain of the microphone signal. In an ideal case the microphone should be calibrated like a sonometer one and be used with a calibrated sound card with precise digital gain control rather than illustrative knob controls.

In the first case, the path from the source to the cancelling speaker was not considered. In this second approach the signal received by the microphone is considered as the 
source which comprehends the environment filtering. In addition, in a system with another architecture and less graphics and filtering, the microphone can be close enough to the cancelling speaker to avoid the power level problem of the first approach related to distances.

\section{c) ANC System Type 3}

The third approach is more complex than the two first ones, it is based on Widrow's system. In this system, like in the second one, the signal captured by the first microphone, placed before the cancelling speaker, is considered as the noise source to be cancelled.

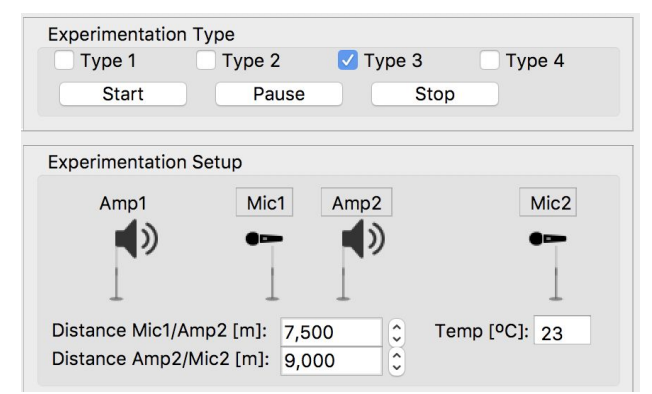

Figure 18. Experimentation Type 3 interface

However, in this case the second microphone is also taken in account in the system (Fig.18). The signal captured by this second microphone is used as the error signal of an adaptive FIR filter that predicts the path between the source and the cancelling speaker, this way the system adapts the cancellation signal according to the error perceived in the cancellation of the last frames(Fig.19).

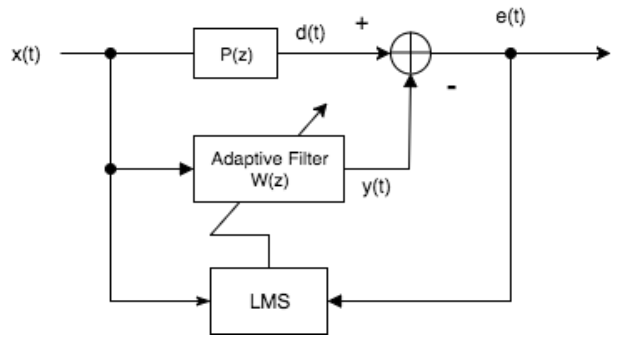

Figure 19. Experimentation Type 3 block-diagram

The signal of the cancelling speaker is the output of the filter and is calculated as the product of the updated filter weights with the reference signal(see equation 15).

$$
\begin{gathered}
y[n]=w^{T}[n] \cdot x[n] \quad \text { equation } 15 \\
\text { where }: w[n]=\text { filter weights }(\text { size } N) \\
x[n]=\text { reference signal }
\end{gathered}
$$

Given a reference frame and the cancellation error captured by the second microphone, the filters weights are updated using a Least Mean Square based approach(equation 17).

$$
\begin{array}{cc}
e[n]=d[n]-y[n] & \text { equation 16 } \\
w[n+1]=w[n]+x[n] \cdot e[n] & \text { equation 17 }
\end{array}
$$

\section{d) ANC System Type 4}


The fourth implementation is very similar to the third one, both microphones are used and an adaptive filtering is implemented, taking profit of the captured error to improve the cancellation. However, in order to meliorate the adaption, a FxLMS approach is implemented.

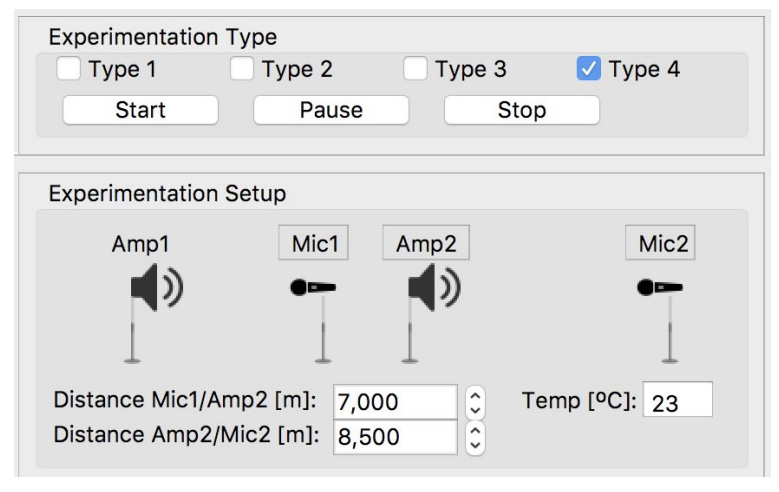

Figure 20. Experimentation Type 4 interface

In this approach, the acoustic path $S(z)$ between the canceling signal sent to the speaker and the response captured by the microphone is considered. Before the commencement of the test, an impulse is emitted by the cancelling amplifier and captured by the error microphone to model the impulse response of this acoustic path between the LMS output signal and the response captured by the microphone error.

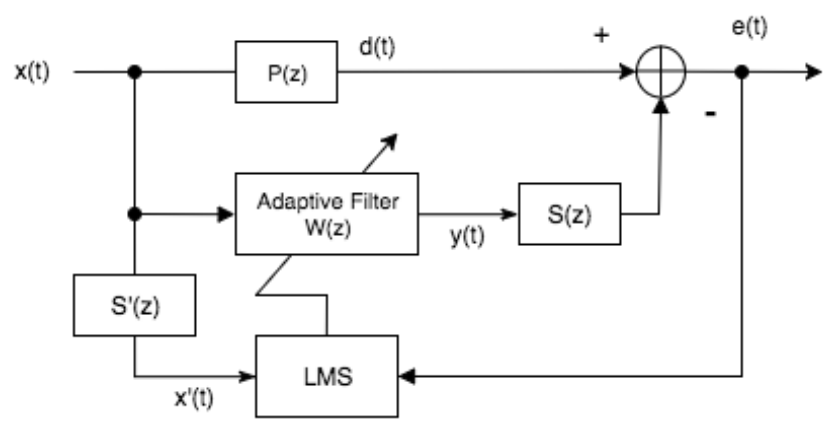

Figure 21. Experimentation Type 4 lock-diagram

The filtering stage is the same than in the last case (equation 15) but, in this case, the calculated path $S(z)$ is taken in account in the filter weights adaption. A filter $S^{\prime}(z)$ identical to the found path $S(z)$ is placed before the LMS stage and taken in account when updating the coefficients of the adaptive filter(equation 18).

$$
\begin{gathered}
w[n+1]=w[n]+x^{\prime} e[n] \quad \text { equation } 18 \\
\text { where : } x^{\prime}[n]=s^{\prime}[n] \otimes x[n]
\end{gathered}
$$




\section{4. $\quad$ Results}

The four implemented systems have been tested in order to study their performance. The ideal to well perform the experimentations and have a comparison with the open spaces would have been to have an anechoic environment available. In the absence of it the different systems have finally been carried out outdoors, at the upc campus nord park. Both speakers were identical, and the results were taken by a sonometer at a distance from the second speaker equal to the distance between speakers.

For the first system, the cancellation has been tested for different cancelling amplifier's powers. The figure 22 shows the cancellation amount found for different powers for a pure tone of $100 \mathrm{~Hz}$. The expected result, given the experimentation setup and the equation 12 was to obtain the best cancellation for a cancelling amplifier's power $6 \mathrm{~dB}$ lower than the source's. As shown in the graph, the result has been the expected with a maximal cancellation for a cancelling speaker power equal to $25 \%$ of the source power, obtaining $13,62 \mathrm{~dB}$ of attenuation.

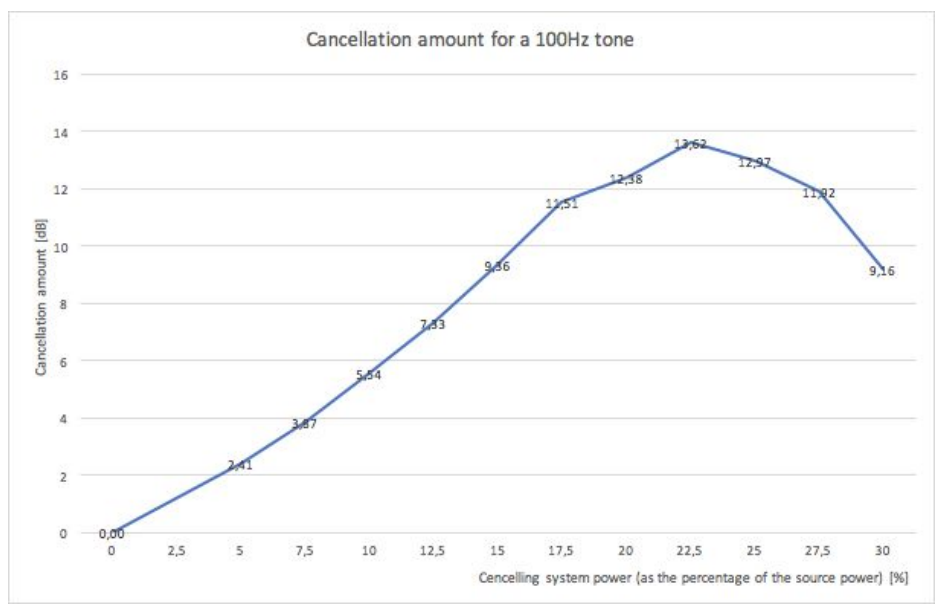

Figure 22. Cancellation amount for a $100 \mathrm{~Hz}$ tone

The first system has also been tested for different tones with an octave interval to see its effectivity range. As seen on the figure 22, the cancellation occurs only for the lower frequencies, approximately until $375 \mathrm{~Hz}$.

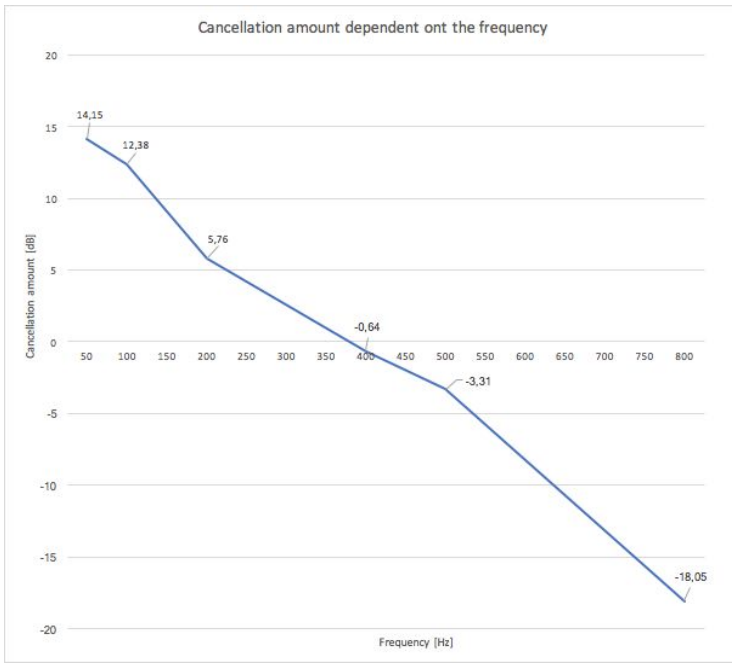

Figure 23. Cancellation dependent on frequency 
To verify the results, the system has also been tested for two white noises, the first one until $500 \mathrm{~Hz}$ and the second one until $2 \mathrm{kHz}$. The result has been very similar for both noises, giving again the same critical frequency near $375 \mathrm{~Hz}$.

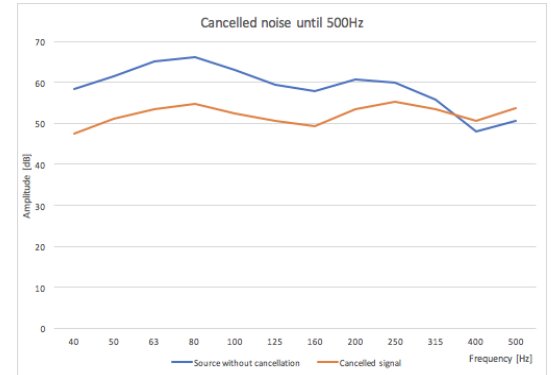

Figure 24. Cancelled noise until $500 \mathrm{~Hz}$

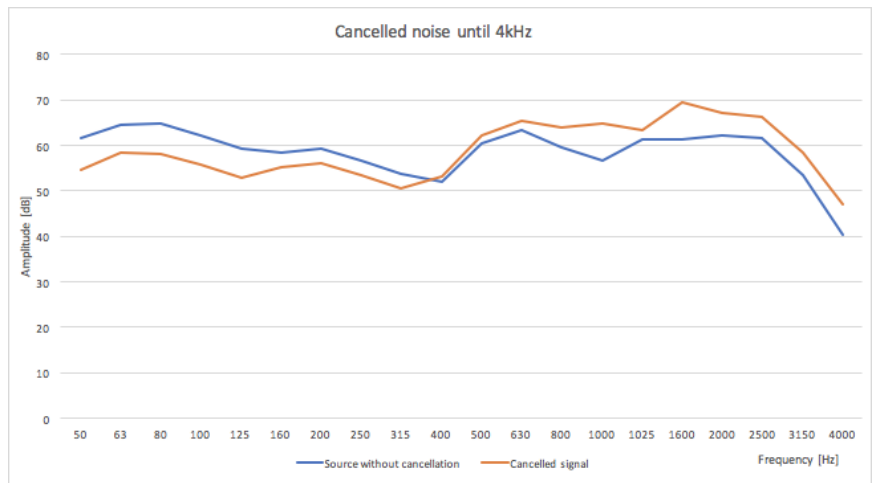

Figure 25. Cancelled noise until $4 \mathrm{kHz}$

To obtain a comparison of the cancellation amount, the second system has been tried in the same conditions than the first, with a $100 \mathrm{~Hz}$ tone. From this comparison we can observe than the first system seems to have some better performance obtaining an attenuation around $4 \mathrm{~dB}$ higher than the second one.
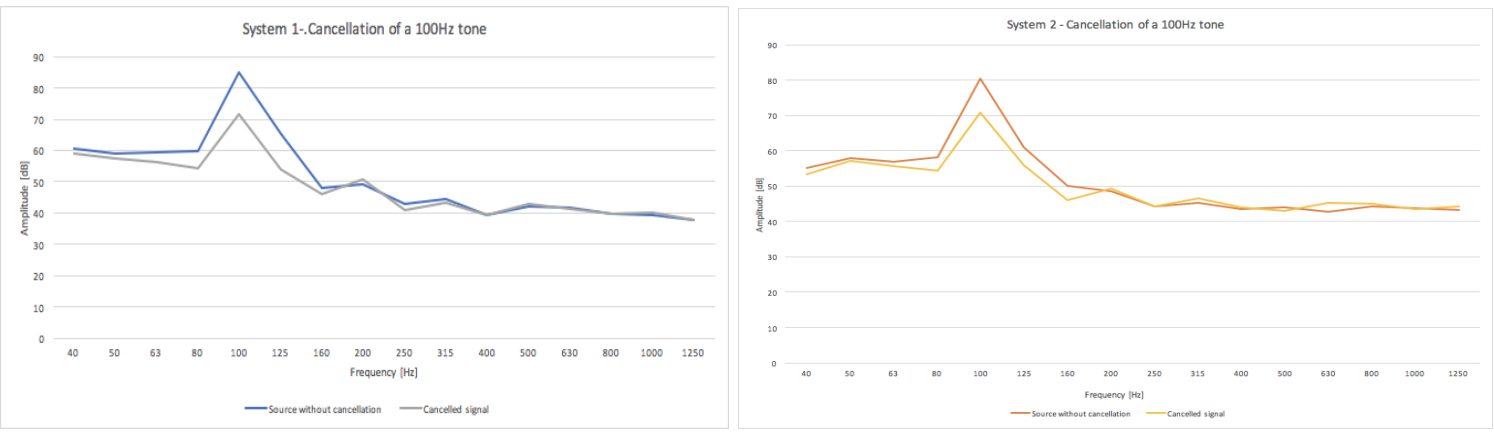

Figure 26. Cancellation amount comparison of systems

Type 1 and Type 2 for a $100 \mathrm{~Hz}$ pure tone

The third and fourth systems have crashed because of the randomness of the environmental noise captured by the error microphone, which has not permitted the system to reach any convergence. 


\section{Budget}

\begin{tabular}{|l|c|c|c|}
\hline \multicolumn{1}{|c|}{ Equipment } & $\begin{array}{c}\text { Approximate cost } \\
\text { per Unit (€) }\end{array}$ & $\begin{array}{c}\text { Number of } \\
\text { Units }\end{array}$ & $\begin{array}{c}\text { Approximate total } \\
\text { Cost (€) }\end{array}$ \\
\hline Flat-response directional speaker & 180 & 2 & 360 \\
\hline Condenser directional microphone & 150 & 2 & 300 \\
\hline $\begin{array}{l}\text { Laptop with the corresponding } \\
\text { specifications }\end{array}$ & 750 & 1 & 750 \\
\hline 2 in/out Sound card & 150 & 1 & 150 \\
\hline XLR-10m wires & 10 & 4 & 40 \\
\hline XLR-Jack adaptor & 5 & Total: & 10 \\
\cline { 2 - 4 } & & & $1610 €$ \\
\hline
\end{tabular}

Table 6. Material Costs

\begin{tabular}{|l|c|c|c|}
\hline \multicolumn{1}{|c|}{ Task } & $\begin{array}{c}\text { Cost per hour } \\
(\boldsymbol{\epsilon})\end{array}$ & $\begin{array}{c}\text { Number of } \\
\text { hours }\end{array}$ & $\begin{array}{c}\text { Approximate total } \\
\text { Cost }(\boldsymbol{\epsilon})\end{array}$ \\
\hline Research & 10 & 140 & 1400 \\
\hline Programming & 10 & 260 & 2600 \\
\hline Experiments & 10 & 60 & 600 \\
\hline Documentation & 10 & 120 & 1200 \\
\hline & & Total: & $€ 4640$ \\
\cline { 2 - 4 } & & &
\end{tabular}

Table 7.Personal Costs

All the used software has been open source, so the software license amortization is not considered. 


\section{Environment Impact}

This work has a very important environmental impact. When we think about sustainability and the environment or people affectance, we always think in air pollution, global warming, deforestation, etc. However, an important factor not taken in account very often is the acoustic pollution. As said by the WHO (World health organization)in their website http://www.euro.who.int/en/home :

"Noise has emerged as a leading environmental nuisance in the WHO European Region, and the public complains about excessive noise more and more often."

"Excessive noise seriously harms human health and interferes with people's daily activities at school, at work, at home and during leisure time. It can disturb sleep, cause cardiovascular and psychophysiological effects, reduce performance and provoke annoyance responses and changes in social behaviour.

Traffic noise alone is harmful to the health of almost every third person in the WHO European Region. One in five Europeans is regularly exposed to sound levels at night that could significantly damage health."

With this application, a system like the one proposed by Lewis Athanas (2011)[13], in which the active noise cancellation is used to attenuate highways, or office workspace noise can be tested. The implemented application can help us in the study of the viability and the performance of active noise cancellation systems that can lead us a step forward in the fight against noise pollution. 


\section{Conclusions and future development:}

Considering the fact of having developed an original project without any guideline and using new programming languages and tools, the satisfaction is absolute. Even if the project has needed to be reconducted into developing a software to test different ANC approaches, the resulting application has resulted very useful to carry out the wanted experimentations. The developed tools like the experimentation selection and setup, the equalizer, the signal generator, etc. have permitted to study different aspects of the performance of some ANC approaches with different complexities.

The first system has worked even better than expected, with a notable attenuation over $13 \mathrm{~dB}$ at the lower frequencies and an effective attenuation frequency range up to $315 \mathrm{~Hz}$ ( $3 \mathrm{~dB}$ of attenuation). The affectation at the very low frequencies $(20 \mathrm{~Hz}-160 \mathrm{~Hz})$ is very significant for being the hardest frequencies to attenuate using passive systems either outdoors or indoors.

The added circuitry of the second system (microphone and wiring) has added an unexpected delay to the captured noise signal, making harder to determinate the correct delay for the best cancellation. However, the second system has resulted in a very good performance also, obtaining only $4 \mathrm{~dB}$ of attenuation less than the first approach, a total of $10 \mathrm{~dB}$ of attenuation in the same conditions. Even if the performance of this second system is worse than the first one, the independence of this approach (not being directly linked to the source) makes it much more adaptable to any situation. However, it is very important to filter the cancelling signal to have the same frequency response for the cancelling source than the noise source either microphone or speaker.

The third and fourth implementations pretended to solve this problem with an adaptive filtering approach to improve the performance of the whole system but they have not worked correctly. The affectation of the environment interferences on the error microphone have made the system crash and not cancel as expected.

The distance checker have also had less accuracy than expected due to the already mentioned hardware effects, like the unbalanced frequency response and environmental effects, like wind. Those factors can affect the caption of the source to be cancelled and the reference microphone to analyze the system output. To have an optimal performance, the microphones should be calibrated class 1 condenser microphones and be provided of a good wind screen to prevent unwanted effects.

In a future development, the adaptive filtering approaches and the distance checker should be reviewed and tested using the professional calibrated condenser microphones.

Moreover the application resources consumption, for real-time graphics, audio streaming and data processing, should also be reviewed and better distributed improving the multiprocess approach, in order to prevent overloading the system. This way the frame size could be reduced resulting in smaller distances for the systems setup, which results in more compact and portable ANC systems, with bigger effectivity ranges solving the distances relation problem. Finally, working with a soundcard with more inputs and outputs could bring the possibility of developing more complex and adapted systems . 


\section{Bibliography:}

[1] P. Lueg et al., "Process of silencing Sound Oscillations" U.S. Patent 2043 416, June 9, 1936.

[2] H. F. Olson et al., "Electronic Sound Absorber" U.S. Patent 2983 790, May 9, 1961

[3] M.E. Hawley and E.D. Smshauser, "Noise Reduction System" U.S. Patent 2972 018, February 14,1961

[4] Widrow, B., J.R. Glover Jr, J.M. McCool, J. Kaunitz, C.S. Williams, R.H. Hearn, J.R. Zeidler, D. Eugene, Jr. and R.C. Goodlin, "Adaptive Noise Cancelling: Principles and Applications", IEEE, 63(12): 1692-1716. 1975

[5] Roshahliza M. Ramli, Ali O. Abid Noor, and Salina Abdul Samad "A Review of Adaptive Line Enhancers for Noise Cancellation" Department of Electrical, Electronics and Systems Engineering Faculty of Engineering and Built Environment Universiti Kebangsaan Malaysia 43600 Bangi, Selangor, MALAYSIA 2012

[6] U. Emborg. "Cabin noise control in the saab 2000 high-speed turboprop aircraft." ISMA23, page 13-25, 1998.

[7] Hirsch, H.G., "HMM adaptation for telephone applications", Proc. European Conf. on Speech Communication and Technology, 1999

[8] Sas, P., Dehandschutter, W., Vecchio, A., Boonen, R., "Active control of sound transmission through a double panel partition", J. Sound Vib. 180, 609-625, 1998.

[9] Guldenschuh ,"Prediction filter design for active noise cancellation headphones" , 2012

[10] Sen M. Kuo, Sohini Mitra, and Woon-Seng Gan, "Active noise control system for headphone applications," IEEE Transactions on Control Systems Technology, vol. 14, pp. 331-335, 2006.

[11] Lloyd Tramell, "Active noise cancellation method for aircraft" U.S. Patent 20150358728 , December 10, 2015

[12] S. Butterworth, "On the theory of filter amplifiers", Admiralty Research Laboratory, October, 1930

[13] Lewis Athanas, "Open Air Noise Cancellation” U.S. Patent 2011/0274283 A1, Jul 212010 